\title{
ТРАНСАКЦИОННЫЕ ИЗДЕРЖКИ В УСЛОВИЯХ ЦИФРОВИЗАЦИИ ЭКОНОМИКИ: ПЕРЕОСМЫСЛИВАЯ Р.КОУЗА
}

\author{
(C) 2020 Буевич Анжелика Петровна \\ кандидат экономических наук, доцент \\ Финансовый университет при Правительстве Российской Федерации, Россия, Москва \\ Email: buanpet@mail.ru \\ (c) 2020 Карамова Ольга Владимировна \\ доктор экономических наук, профессор \\ Финансовый университет при Правительстве Российской Федерации, Россия, Москва \\ Email: okaramova@fa.ru
}

В статье рассматривается развитие теории трансакционных издержек, впервые выдвинутой американским экономистом, лауреатом Нобелевской премии по экономике Рональдом Коузом. Статья посвящена анализу разных классификаций трансакционных издержек, которые раскрывают взаимосвязь между трансакциями, трансакционными издержками и трансформацией институтов.

Ключевые слова: трансакции, трансакционные издержки, неоинституционализм, издержки поиска информации, издержки ведения переговоров, издержки спецификации и защиты прав собственности, издержки оппортунистического поведения.

Одним из ключевых направлений развития современной экономической науки выступает неоинституционализм, составляющей которого является теория трансакционных издержек. Именно трансакционные издержки выполняют роль центральной категории неоинституционального анализа, объясняющей большинство процессов, происходящих в экономике. Если в рамках ортодоксальной неоклассической теории рынок представлялся совершенным механизмом, в котором не было необходимости в учете издержек по обслуживанию заключаемых сделок, то осознание ключевого значения трансакционных издержек для деятельности экономической системы произошло как раз в рамках новой институциональной теории, и связано оно с именем Р. Коуза.

Именно этот экономист, будучи одним из родоначальников нового институционализма, сумел продемонстрировать необходимость проведения переговоров при заключении любой сделки, осуществления надзора за ее реализацией, установления взаимосвязей и устранения разногласий.

В соответствии с первыми определениями трансакционных издержек Р.Коуза, они представлялись «издержками использования механизма цен», «издержками осуществления трансакций обмена на открытом рынке», «издержками рыночных трансакций» или просто

«рыночными издержками» [4]. Впоследствии С.Далманом была предложена трактовка трансакционных издержек как издержек на сбор и обработку информации, на проведение переговоров и принятие решений, на осуществление контроля и на принуждение партнеров к выполнению условий контракта [8].

Позже под трансакционными издержками стали понимать любые виды издержек, появляющихся в результате взаимодействия экономических агентов вне зависимости от места его реализации - на рынке или внутри организаций, так как в результате любого делового сотрудничества, происходящего в рамках иерархических структур (таких, как фирмы), также возникают трения и потери. Категория трансакции описывает различные аспекты обмена, причем как материальные (обмен товарами), так и контрактные (обмен различными видами деятельности или юридическими обязательствами). Данный факт значим для нас тем, что в современных условиях экономика (мировая и национальная) находится на пути новой трансформации, связанной с глобальной цифровизацией. В основе цифровой экономики лежат именно нематериальные активы, для нее характерны массовое использование данных, повсеместное внедрение многосторонних бизнес-моделей, а также сложности в определении юрисдикции, где создается стоимость. 
Продолжая изучать Р.Коуза, мы видим, что убежденность исследователя в том, что без понимания трансакционных издержек невозможны осознание деятельности любой экономической системы и проведение анализа большинства проблем с целью получения оснований для принятия решений, позволила ему объяснить, «что же именно фирма покупает, производит и продает» [4].

Действительно, даже при децентрализованном ведении производства (на основе контрактов между индивидуумами) невозможность осуществления трансакций без определенных издержек объясняет возникновение фирм с целью осуществления действий, которые в противном случае совершались бы через рыночные трансакции (при меньших внутрифирменных издержках по сравнению с издержками рыночных трансакций).

Следовательно, именно трансакционные издержки становятся для желающих торговать стимулом к введению различных форм деловой практики, способствующих сокращению трансакционных издержек в случае, когда затраты по выработке таких форм становятся меньше, чем экономия на трансакционных издержках.

Р.Коуз в своих работах раскрыл фундаментальную роль трансакционных издержек в процессе формирования институтов, составляющих экономическую систему. Развитие его идей проявилось в появлении различных подходов для классификации трансакционных издержек. Так, вдохновившись работами Р. Коуза, О.Уильямсон [5]. выделил две ключевые группы трансакционных издержек: ex ante (издержки, образуемые до сделки) и ex post (издержки, образуемые после сделки).

Позже данная классификация в западной литературе была расширена, о чем, собственно, говорит Р.И.Капелюшников [2], выделяя пять классов издержек трансакции, подчеркивая отсутствие общепринятой классификации. Одной из ключевых идей теории трансакционных издержек Р.Коуза является минимизация затрат. Экономист считает, что большинство из происходящего в экономике направлено на сокращение трансакционных издержек, либо на создание возможности для этого [4]. Обращаясь к идеям Рональда Коуза, в качестве основных преимуществ цифровизации глобальной экономики эксперты называют снижение трансакционных издержек, формирование новых бизнес-моделей и, как следствие, исключение посредников посредством реализации прямого взаимодействия между потребителем и поставщиком [10]. Попытаемся раскрыть данную мысль в процессе анализа трансакционных издержек в условиях цифровой экономики в рамках имеющейся классификации.

Издержки поиска информации связны с поиском альтернатив и обработкой больших массивов данных [6]. Бесспорным является тот факт, что современная экономика характеризуется значительным объемом разного рода данных, разнообразием и скоростью их обновления. В результате стандартные методы и инструменты работы с информацией становятся недостаточно эффективными.

Снижение затрат на сбор и обработку информации сокращает и трансакционные издержки. Помимо широкого спектра технологических решений в области поиска информации посредством применения различного рода поисковых систем, в условиях цифровой экономики упрощается задача привлечения целевой аудитории посредством сети Интернет [7].

Одним из технологических прорывов в контексте сказанного стала концепция блокчейна, предложенная Сатоши Накамото [9] в 2008 году и реализованная впервые в 2009 году в качестве компонента криптовалюты - биткоина. В техническом аспекте блокчейн представляет собой базу данных - цифровой реестр данных об осуществленных сделках, транзакциях, выполненных контрактах. В нем могут храниться любые данные, распределенные по всему миру, а не находящиеся на одном сервере. Такая децентрализация информации защищает реестр от внесения внешних изменений, что позволяет обеспечить прозрачность и актуальность хранящихся в нем данных. Использование данной технологии может сократить трансакционные издержки компаний в зависимости от вида деятельности и отрасли от 20 до 40\% от их изначального объема.

Издержки ведения переговоров в первую очередь связаны с обсуждением условий обмена, выбора формы сделки и т.п. Современные средства коммуникации позволяют решать все эти вопросы без личной встречи заинтересованных сторон, опосредованно (косвенно, на расстоянии). При этом в условиях цифровой экономики существует возможность автоматизации коммуникаций продавца с потребителем. 
Данное обстоятельство объясняет популярность интернет-торговли, сократившей цепочку посредников. Для проведения переговоров также существует масса технических решений, позволяющих обсуждать условия заключения контрактов в онлайн среде с применением возможностей аудио и видео конференций. Также заключение контрактов упростилось при внедрении электронной цифровой подписи, которая позволяет заключать контракты в электронной форме с обеспечением их юридической силы.

Еще одним новшеством стал умный контракт (Smart contract). Идея его была предложена Ником Сабо в 1994 году, реализация же стала возможной только в 2008 году, что связано с появлением все той же технологии блокчейн, о которой говорилось выше.

Умный контракт является компьютерным алгоритмом, предназначенным для заключения и поддержания договорных обязательств посредством применения технологии блокчейн. Обеспечивая гарантию перевода средств или выполнения других действий после исполнения сторонами контракта указанных в нем обязательств, он может быть использован для любых сделок. Автоматизированное выполнение обязательств в рамках контракта возможно в специальной среде, позволяющей автоматизирование выполнения всех его пунктов. При этом все взаимоотношения между сторонами должны быть математически формализованы и иметь четкую логику исполнения. Это позволяет алгоритму смарт контракта отследить достижение или нарушение его пунктов и принимать соответствующие решения в автоматическом режиме для обеспечения достоверности исполнения договорных обязательств.

Издержки измерения. Данный класс трансакционных издержек предполагает проведение измерений, затраты на которые будут расти с увеличением требований к точности. А вот снизить данные издержки можно путем стандартизации. При этом цифровизация меняет процессы стандартизации. Так, цифровая экономика через призму стандартизации может предполагать, например, создание цифровой модели изделия и проведение виртуальных измерений, организацию электронной сертификации или применение цифровых процессов для создания стандартов. Кроме того, применение информационных технологий позволяет хранить огром- ный объем данных, связанных с измерениями.

Издержки спецификации и защиты прав собственности. Следует отметить, что приобретение прав собственности не только практического, но и академического значения, а также понимание основательности правового аспекта спецификации прав собственности и обмена ими, сопряженного со значительными издержками, является центральным достижением институционализма. В то же время для цифровой экономики характерна тенденция качественных трансформаций традиционных отношений собственности в сторону постоянного размывания прав собственности, которое трактуется в экономике как неполнота спецификации интеллектуальной собственности из-за искаженности, отсутствия точной определенности и полноценной защиты этих прав [1].

Это связано, во-первых, с появлением новых объектов собственности (массивов больших данных, аватарок, геймплееров и др.). Во-вторых, со сложностью определения субъектов собственности. Несмотря на то, что сегодня многие цифровые объекты, с точки зрения действующего законодательства, не считаются объектами прав собственности, а возникновение их происходит лишь в рамках договоров между контрагентами, в ближайшем будущем те же аватарки, никнеймы, геймплееры или массивы больших данных в том или ином виде могут быть приравнены к охраняемым результатам интеллектуальной деятельности. В-третьих, с трудностью или невозможностью обеспечения защиты. Полагаем, что ошибкой будет адаптировать их защиту к традиционным договорным формам обращения с так называемыми аналоговыми объектами. В-четвертых, с ограничениями со стороны государства. С другой стороны, цифровая экономика может предложить ряд решений для данных проблем, например платформенные решения, основанные на технологии распределенных реестров и позволяющие любым пользователям эффективно управлять своей интеллектуальной собственностью с их помощью. Действительно, цифровые сервисы, платформы предоставляют возможность конструировать более сложные взаимоотношения, обеспечивать их своевременное фиксирование и исполнение обязательств, а также оперативно получать и использовать интеллектуальный и творческий продукт. И здесь на помощь может прийти технология блокчейн, позволяющая зафиксировать 
все стадии жизненного цикла интеллектуальной собственности от момента ее создания и каждого случая использования, формировать распределительный реестр, хранящий информацию о конечном продукте.

Издержки оппортунистического поведения. Пожалуй, данный класс издержек является самым скрытым и сложным, но, согласимся с Р.И.Капелюшниковым [2], самым интересным элементом трансакционных издержек с экономической точки зрения. Бесспорным является тот факт, что недобросовестное поведение, нарушающее условия сделки или нацеленное на получение односторонних выгод в ущерб партнеру, существенно усложняет экономические проблемы участников сделки и лежит в основе действительной или мнимой информационной асимметрии.

Применительно к цифровой экономике к издержкам оппортунистического поведения следует отнести также ущерб от «пиратства» и затраты на борьбу с ним. С целью сокращения таких издержек в частных и государственных учреждениях создаются целые структуры, сложные и дорогостоящие, структуры, в задачи которых входит контроль за поведением контрагентов, выявление случаев оппортунизма, применение санкций и т.п. Вместе с тем сами иерархические структуры являются благодатной почвой для оппортунистического поведения, что определяет необходимость введения правил, ограничивающих отклонения в поведении агентов от интересов организации. В рамках цифровой экономики также существуют решения, направленные на снижение издержек оппортунистического поведения. Например, появившиеся онлайнагрегаторы - электронные площадки, объединяющие множество поставщиков (источников информации) на одном ресурсе. Как раз они мо- гут решить традиционные проблемы оппортунистического поведения посредством взаимного рейтингования. Например, в той же системе «Яндекс-такси» водитель и пассажир выставляют друг другу рейтинг, при этом начинает действовать система взаимного рейтингования и накопления репутаций, способствующая снижению риска оппортунистического поведения, причем как водителя, так и пассажира.

Оппортунистическое поведение, проявляющееся не в рамках определенной иерархии, а в рамках децентрализованной закрытой и надежной системы гарантированных платежей, может контролироваться посредством технологии блокчейн, обеспечивающей прозрачность транзакций, информация о которых находится в открытом доступе. То есть созданный реестр будет представлять собой хранилище репутации контрагентов.

Таким образом, проведенный нами анализ трансакционных издержек в условиях цифровой экономики демонстрирует, что теория Р. Коуза в рамках цифровой экономики приобретает новый смысл, который заключается в радикальном снижении уровня трансакционных издержек посредством цифровизации и применения новых технологий, в том числе блокчейна. Очевидно, что появление новых инструментов и широкое внедрение цифровых технологий способствуют ускорению и снижению рыночных трансакций. Переосмысливая Р. Коуза, становится понятной его логика о снижении роли фирм, развитии сетевых инструментов, основанных на рыночных трансакциях, а в условиях цифровизации экономики современного общества - актуальность его теории, применение которой представляет интерес для преодоления негативных процессов в сегодняшней экономике Российской Федерации.

\section{Библиографический список}

1. Беляева, И.Ю., Данилова, О.В., Федотова, М.А. Тенденции трансформации собственности и развитие корпоративных отношений в цифровой экономике / И. Ю.Беляева, О.В.Данилова, М.А.Федотова // Вестник Астраханского технического университета. - 2020.- № 1.- С.7-16.

2. Капелюшников, Р. И.Экономическая теория прав собственности.-М.: ИМЭМО, 1990.-90 с.

3. Коммонс, Дж. Р. Институциональная экономика // TERRA ECONOMICUS, том 10._- № 3, 2012.- C.69-76.

4. Коуз, Р. Фирма, рынок и право / Пер. с англ.-М.: Новое издательство, 2007. - 224 с.

5. Уильямсон, О. Экономические институты капитализма / Оливер И. Уильямсон.- СПб, Лениздат, 1996. - 704 c.

6. Трубецкая О. В. Институциональные изменения и цифровая экономика // Экономические науки. 2019 . № 12 (181) c.74-78. DOI: $10.14451 / 1.181 .74$. 
7. Осипов Ю.М., Юдина Т. Н., Гелисханов И. З. Информационная и цифровая экономика: концепт, основные параметры и механизмы реализации // Вестник Московского университета. Серия 6: Экономика, издательство Изд-во Моск. ун-та (М.), 2019. № 3. с. 51-60.

8. Dahlman, C. J. The Problem of Externality // The Journal of Law and Economics. - Vol. 22 (April 1979). - № 1.— P. 148.

9. Nakamoto, S. Bitcoin: A Peer-to-Peer Electronic Cash System, The Cryptography Mailing list, 2008. // [Электронный ресурс] URL: https://bitcoin.org/bitcoin.pdf (Дата обращения - 02.09.2020).

10. Tapscott, $D$. The Digital Economy: Promise and Peril In The Age of Networked Intelligence. McGrawHill; 1995.$342 \mathrm{p}$. 